Article

\title{
Temperature-Dependent Sellmeier Equations of IR Nonlinear Optical Crystal $\mathrm{BaGa}_{4} \mathrm{Se}_{7}$
}

\author{
Naixia Zhai ${ }^{1,2}$, Chao $\mathrm{Li}^{1,2}$, Bo Xu ${ }^{1,2}$, Lei Bai ${ }^{1}$, Jiyong Yao ${ }^{1, *}$, Guochun Zhang ${ }^{1}$, Zhanggui Hu ${ }^{1}$ \\ and Yicheng $\mathrm{Wu}^{1}$ \\ 1 Beijing Center for Crystal Research and Development, Key Laboratory of Functional Crystals and Laser \\ Technology, Technical Institute of Physics and Chemistry, Chinese Academy of Sciences, Beijing 100190, \\ China; nxzhai@mail.ipc.ac.cn (N.Z.); 1cscdx@163.com (C.L.); xubo@mail.ipc.ac.cn (B.X.); \\ lbai@mail.ipc.ac.cn (L.B.); gczhang@mail.ipc.ac.cn (G.Z.); hu@mail.ipc.ac.cn (Z.H.); \\ ycwu@mail.ipc.ac.cn (Y.W.) \\ 2 University of Chinese Academy of Sciences, Beijing 100049, China \\ * Correspondence: jyao@mail.ipc.ac.cn; Tel.: +86-10-8254-3725
}

Academic Editors: Ning Ye and Rukang Li

Received: 19 January 2017; Accepted: 14 February 2017; Published: 23 February 2017

\begin{abstract}
The thermal dependent principal refractive indices of a new promising IR nonlinear optical crystal $\mathrm{BaGa}_{4} \mathrm{Se}_{7}$ at wavelengths of $0.546,0.5806,0.644,0.7065,1.530,1.970$, and $2.325 \mu \mathrm{m}$ were measured by using the vertical incidence method within the temperature range from 25 to $150{ }^{\circ} \mathrm{C}$. We derived equations of thermal refractive index coefficients as a function of wavelength that could be used to calculate the principal thermal refractive indices at different wavelengths. The temperature-dependent Sellmeier equations were also obtained and used to calculate the phase matching angles for the optical parametric process of $\mathrm{BaGa}_{4} \mathrm{Se}_{7}$ crystal at different temperatures.
\end{abstract}

Keywords: $\mathrm{BaGa}_{4} \mathrm{Se}_{7}$; nonlinear optical crystal; thermal refractive index coefficient; temperaturedependent Sellmeier equation

\section{Introduction}

At present, there has been an intensive trend to explore novel mid-far IR nonlinear optical (NLO) crystals for generating mid-far IR laser sources, which have many important applications including atmospheric monitoring, laser radar, and laser guidance [1-4]. In IR nonlinear optics, the chalcopyrite-type $\mathrm{AgGaQ}_{2}(\mathrm{Q}=\mathrm{S}, \mathrm{Se})$ and $\mathrm{ZnGeP}_{2}$ crystals have been practically used since the 1970s. However, $\mathrm{AgGaQ}_{2}\left(\mathrm{Q}=\mathrm{S}\right.$, Se) has a low laser-damage threshold, and $\mathrm{ZnGeP}_{2}$ exhibits strong two-photon absorption of the conventional $1064 \mathrm{~nm}$ pumping laser sources, severely limiting their applications[5-7].

Recently, $\mathrm{BaGa}_{4} \mathrm{Se}_{7}$ (BGSe) was reported as a promising NLO crystal for practical applications in the mid-IR spectral range. The crystal belongs to the monoclinic space group Pc. It possesses intriguing overall properties for IR NLO applications including wide transparent range ( 0.47 to 18 $\mu \mathrm{m})$, suitable birefringence, large nonlinear optical coefficients, and high laser damage threshold [8-12]. The outstanding properties of $\mathrm{BaGa}_{4} \mathrm{Se}_{7}$ have been exemplified by some recent laser experiments [13-17]. Given the outstanding NLO properties and the preliminary laser experiment results, BGSe may have attractive applications in three aspects: (1) realizing mid IR output using the conventional $1 \mu \mathrm{m}$ laser as the pumping source; (2) the generation of IR laser in the long wavelength, especially the $8-15 \mu \mathrm{m}$ range; (3) the second-harmonic generation the $\mathrm{CO}_{2}$ laser.

During high-power laser output process, the effect of self-heating in NLO crystal leads to variation of refractive index, and thus the phase-matching (PM) direction will be distorted, which could dramatically influence the stability of output power and the output mode of the laser cavity. To solve 
this problem, NLO crystal can be attached to some cooling device to obtain a stable temperature. To predict the PM angles more accurately at elevated temperature, it is of significance to determine the principal refractive indices at different temperatures and to obtain the thermal refractive index coefficients and the temperature-dependent Sellmeier equations, which are important parameters for designing a frequency-conversion device at the actual operating temperature.

In this work, we determine the principal refractive indices at different temperatures of BGSe crystal, and present its thermal refractive index coefficients and temperature-dependent Sellmeier equations for the first time.

\section{Results}

\subsection{Thermal Refractive Index Coefficients}

As shown in Table 1, refractive indices $n_{x}, n_{y}$, and $n_{z}$ all increase slowly with the increased temperature at different wavelengths. For a specific wavelength, the index can be assumed as a linear variation with increased temperature, which could be expressed as

$$
n=n_{0}+d n / d T\left(T-T_{0}\right)
$$

where $n$ is the refractive index at temperature $T, n_{0}$ is the refractive index at $T_{0}$, and $d n / d T$ is the thermal refractive index coefficient.

Table 1. Principal refractive indices of $\mathrm{BaGa}_{4} \mathrm{Se}_{7}$ crystal.

\begin{tabular}{|c|c|c|c|c|c|c|c|}
\hline \multicolumn{2}{|c|}{$\lambda(\mu \mathrm{m}) / \mathrm{T}\left({ }^{\circ} \mathrm{C}\right)$} & \multirow{2}{*}{$\begin{array}{c}25 \\
2.66645\end{array}$} & \multirow{2}{*}{$\begin{array}{c}50 \\
2.66960\end{array}$} & \multirow{2}{*}{$\begin{array}{c}80 \\
2.67344\end{array}$} & \multirow{2}{*}{$\frac{100}{2.67597}$} & \multirow{2}{*}{$\begin{array}{c}120 \\
2.67877\end{array}$} & \multirow{2}{*}{$\begin{array}{c}150 \\
2.68300\end{array}$} \\
\hline & $n_{x}$ & & & & & & \\
\hline 0.546 & $n_{y}$ & 2.68304 & 2.68676 & 2.69131 & 2.69419 & 2.69726 & 2.70200 \\
\hline & $n_{z}$ & 2.77179 & 2.77628 & 2.78191 & 2.78551 & 2.78945 & 2.79520 \\
\hline \multirow{3}{*}{0.5875} & $n_{x}$ & 2.62699 & 2.6296 & 2.63275 & 2.6348 & 2.6371 & 2.64033 \\
\hline & $n_{y}$ & 2.64356 & 2.64675 & 2.65052 & 2.65282 & 2.65552 & 2.65961 \\
\hline & $n_{z}^{y}$ & 2.72365 & 2.72722 & 2.73171 & 2.73443 & 2.73755 & 2.74210 \\
\hline \multirow{3}{*}{0.644} & $n_{\mathrm{x}}$ & 2.58907 & 2.59125 & 2.59385 & 2.59558 & 2.59744 & 2.60005 \\
\hline & $n_{\mathrm{y}}$ & 2.60532 & 2.60812 & 2.61143 & 2.61328 & 2.61574 & 2.61882 \\
\hline & $n_{\mathrm{z}}$ & 2.67846 & 2.68136 & 2.68502 & 2.68711 & 2.68956 & 2.69329 \\
\hline \multirow{3}{*}{0.7065} & $n_{\mathrm{x}}$ & 2.55958 & 2.56149 & 2.56376 & 2.56512 & 2.56688 & 2.56905 \\
\hline & $n_{\mathrm{y}}$ & 2.57556 & 2.57800 & 2.58081 & 2.58253 & 2.58465 & 2.58754 \\
\hline & $n_{\mathrm{z}}$ & 2.6439 & 2.64641 & 2.64945 & 2.65118 & 2.65333 & 2.65643 \\
\hline \multirow{3}{*}{1.530} & $n_{\mathrm{x}}$ & 2.46278 & 2.46442 & 2.46615 & 2.46721 & 2.46829 & 2.46947 \\
\hline & $n_{\mathrm{y}}$ & 2.47979 & 2.48122 & 2.48295 & 2.48356 & 2.48503 & 2.48688 \\
\hline & $n_{\mathrm{z}}$ & 2.53538 & 2.5368 & 2.53808 & 2.53914 & 2.53991 & 2.54222 \\
\hline \multirow{3}{*}{1.970} & $n_{\mathrm{x}}$ & 2.45312 & 2.45536 & 2.45634 & 2.45717 & 2.45821 & 2.45955 \\
\hline & $n_{\mathrm{y}}$ & 2.46986 & 2.47120 & 2.47316 & 2.47437 & 2.47499 & 2.47719 \\
\hline & $n_{\mathrm{z}}$ & 2.52443 & 2.52577 & 2.52757 & 2.52808 & 2.52903 & 2.53065 \\
\hline \multirow{3}{*}{2.325} & $n_{\mathrm{x}}$ & 2.44903 & 2.45101 & 2.45229 & 2.45303 & 2.45402 & 2.45508 \\
\hline & $n_{\mathrm{y}}$ & 2.46581 & 2.46738 & 2.4692 & 2.46984 & 2.47082 & 2.4727 \\
\hline & $n_{\mathrm{z}}$ & 2.51973 & 2.52116 & 2.52268 & 2.5233 & 2.52415 & 2.52584 \\
\hline
\end{tabular}

According to the measured principal indices, the relationship between $d n / d T$ of the principal refractive indices and the wavelength $\lambda$ could be fitted, shown in Equation(2):

$$
\begin{aligned}
& d n_{x} / d T=\left(0.6837 / \lambda^{3}-1.7607 / \lambda^{2}+1.6316 / \lambda+0.0318\right) \times 10^{-4} \\
& d n_{y} / d T=\left(0.2692 / \lambda^{3}-0.3112 / \lambda^{2}+0.2201 / \lambda+0.4867\right) \times 10^{-4} \\
& d n_{z} / d T=\left(0.7223 / \lambda^{3}-1.5170 / \lambda^{2}+1.2953 / \lambda+0.1296\right) \times 10^{-4}
\end{aligned}
$$


where $\lambda$ is in micrometer and $0.254 \mu \mathrm{m} \leq \lambda \leq 2.325 \mu \mathrm{m}$. The thermal refractive index coefficients for $n_{x}$, $n_{y}$, and $n_{z}$ were calculated by monadic linear regression method and are given in Table 2 . Table 2 shows that these constants are all positive with magnitude level of $10^{-4}$. Refractive indices corresponding to different wavelengths at different temperatures were calculated by using Equations (1) and (2) ( $T_{0}$ is $25^{\circ} \mathrm{C}, n_{0}$ is the experimental value of refractive index at $\left.25^{\circ} \mathrm{C}\right)$. Figure 1 shows the theoretical and measured values of $n_{x}, n_{y}$, and $n_{z}$. The difference between the measured and calculated values was less than $2 \times 10^{-4}$. This result verifies the reliability of Equation (2). The coefficients of Equation (2) are listed in Table 2.

Table 2. Thermal refractive index coefficients $\left(\times 10^{-5}\right)$ of $\mathrm{BaGa}_{4} \mathrm{Se}_{7}$ crystal at different temperatures.

\begin{tabular}{lllllll}
\hline \multirow{2}{*}{$(\mu \mathrm{m})$} & \multicolumn{3}{l}{$\boldsymbol{d} n_{\boldsymbol{x}} / d T$} & \multicolumn{2}{l}{$\boldsymbol{d} n_{y} / d T$} & \multicolumn{2}{l}{$d n_{z} / d T$} \\
\cline { 2 - 6 } & Experimental & Calculated & Experimental & Calculated & Experimental & Calculated \\
\hline 0.546 & 13.20 & 13.14 & 15.10 & 15.00 & 18.70 & 18.51 \\
0.5875 & 10.70 & 10.79 & 12.70 & 12.87 & 14.70 & 15.01 \\
0.644 & 8.79 & 8.80 & 10.80 & 10.86 & 11.80 & 11.88 \\
0.7065 & 7.58 & 7.52 & 9.54 & 9.38 & 9.96 & 9.72 \\
1.53 & 5.39 & 5.37 & 5.56 & 5.73 & 5.23 & 5.30 \\
1.97 & 4.86 & 4.96 & 5.78 & 5.53 & 4.86 & 4.91 \\
2.325 & 4.69 & 4.62 & 5.34 & 5.45 & 4.71 & 4.64 \\
\hline
\end{tabular}
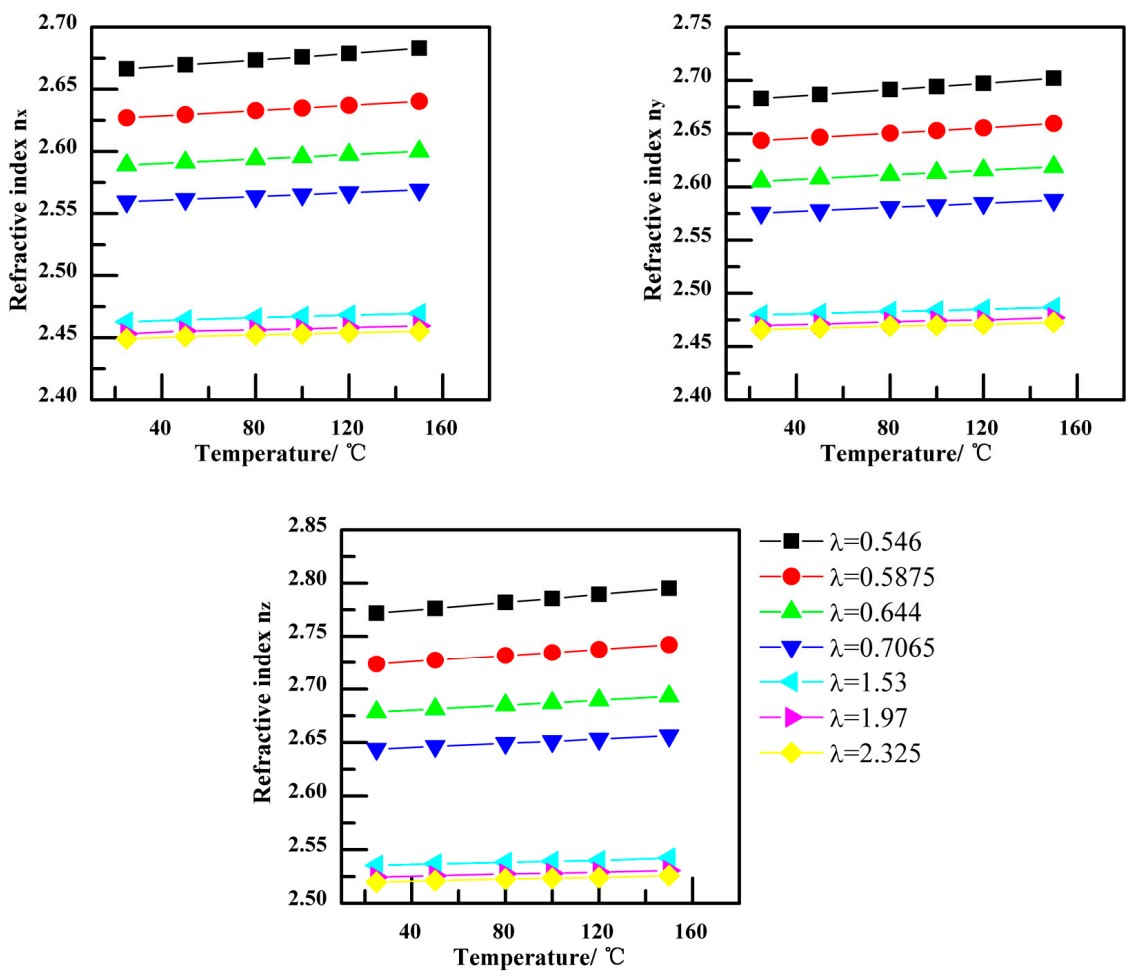

Figure 1. Theoretical and measured values of $n_{x}, n_{y}$, and $n_{z}$.

\subsection{Sellmeier Equationsof $\mathrm{BaGa}_{4} \mathrm{Se}_{7}$ Crystal}

The Sellmeier equation of given temperature can be fit as Equation (3) and the Sellmeier coefficients are listed in Table 3. The difference between the measured and calculated values was less than $3.6 \times 10^{-4}$.

$$
n^{2}(i, T)=A+B /\left(\lambda^{2}-C\right)-D \lambda^{2}\left(I=x, y, z ; T /{ }^{\circ} \mathrm{C}=25,50,80,100,120,150\right)
$$


Table 3. The Sellmeier coefficients $\left(\times 10^{-5}\right)$ of $\mathrm{BaGa}_{4} \mathrm{Se}_{7}$ crystal at different temperatures.

\begin{tabular}{cccccc}
\hline $\mathbf{T}\left({ }^{\circ} \mathbf{C}\right)$ & Sellmeier & $\mathbf{A}$ & $\mathbf{B}$ & $\mathbf{C}$ & $\mathbf{D}$ \\
\hline \multirow{3}{*}{25} & $n_{x}$ & 5.96012 & 0.24529 & 0.08482 & 0.00163 \\
& $n_{y}$ & 6.0459 & 0.24249 & 0.08794 & 0.00218 \\
& $n_{z}$ & 6.31414 & 0.27001 & 0.10096 & 0.00305 \\
\hline \multirow{3}{*}{50} & $n_{x}$ & 5.96791 & 0.24482 & 0.08687 & 0.00114 \\
& $n_{y}$ & 6.0502 & 0.24582 & 0.08787 & 0.00169 \\
& $n_{z}$ & 6.32003 & 0.27192 & 0.10225 & 0.0029 \\
\hline \multirow{3}{*}{80} & $n_{x}$ & 5.97698 & 0.24475 & 0.08903 & 0.0018 \\
& $n_{y}$ & 6.05737 & 0.24815 & 0.08893 & 0.00138 \\
& $n_{z}$ & 6.3241 & 0.27579 & 0.10323 & 0.00225 \\
\hline \multirow{3}{*}{100} & $n_{x}$ & 5.98331 & 0.24424 & 0.09079 & 0.0023 \\
& $n_{y}$ & 6.06074 & 0.24965 & 0.08977 & 0.00131 \\
& $n_{z}$ & 6.33053 & 0.27559 & 0.10525 & 0.00295 \\
\hline \multirow{3}{*}{120} & $n_{x}$ & 5.98866 & 0.24496 & 0.09186 & 0.00242 \\
& $n_{y}$ & 6.06751 & 0.25147 & 0.08998 & 0.0019 \\
& $n_{z}$ & 6.33286 & 0.27849 & 0.10584 & 0.00265 \\
\hline \multirow{2}{*}{150} & $n_{x}$ & 5.99506 & 0.24542 & 0.09425 & 0.0026 \\
& $n_{y}$ & 6.07652 & 0.25243 & 0.09205 & 0.00178 \\
& $n_{z}$ & 6.34616 & 0.27808 & 0.10862 & 0.00363 \\
\hline
\end{tabular}

\subsection{Temperature-Dependent Sellmeier Equations}

The temperature-dependent Sellmeier equations of $n_{x}, n_{y}$, and $n_{z}$ were obtained by using the least-square-fit method, as shown in Equation (4) and Table 4, where iis $x, y$, or $z, \lambda$ is the wavelength in micrometer, and $A, B, C, D, E, F$, and $G$ are constants.

$$
n^{2}(i, \lambda, T)=A+E T+(B+F(T-25) \times(T+G)) /\left(\lambda^{2}-C\right)+D \lambda^{2}(i=x, y, z) .
$$

Average differences between calculated and experimental indices are found to be in the order of $2.8 \times 10^{-4}, 2.4 \times 10^{-4}$ and $2.7 \times 10^{-4}$ for $n_{\mathrm{x}}, n_{\mathrm{y}}$ and $n_{\mathrm{z}}$, respectively. Fitting quality is also demonstrated by the fact that maximum difference (accounting for all principal indices) between theoretical and measured values is found to be $5 \times 10^{-4}$, that is still within our experimental accuracy.

Table 4. Constants in Equation (4).

\begin{tabular}{llllllll}
\hline Coeffecient & $\boldsymbol{A}$ & $\boldsymbol{B}$ & $\boldsymbol{C}$ & $\boldsymbol{D}$ & $\boldsymbol{E}$ & $\boldsymbol{F}$ & $\boldsymbol{G}$ \\
\hline$n_{x}$ & 5.9622 & 0.2375 & 0.090768 & -0.002209 & 0.000205 & $8.0 \times 10^{-8}$ & 1027.6 \\
$n_{y}$ & 6.03935 & 0.240995 & 0.08975 & -0.00175 & 0.0002358 & $8.0 \times 10^{-8}$ & 1263.6 \\
$n_{z}$ & 6.31176 & 0.26518 & 0.10476 & -0.00299 & 0.000191 & $1.1 \times 10^{-7}$ & 1228.7 \\
\hline
\end{tabular}

Table 5 lists the calculated phase matching angles in the $x z$ plane for $3900 \mathrm{~nm}$ output OPO pumped by $1064 \mathrm{~nm}$ laser $(1064 \mathrm{~nm} \rightarrow 3900 \mathrm{~nm}+1463 \mathrm{~nm})$, based on the above Sellmeier equations. It is shown the influence of temperature on the PM angle is not obvious below $80^{\circ} \mathrm{C}$.

Table 5. Calculated phase matching angles for $1064 \mathrm{~nm} \rightarrow 3900 \mathrm{~nm}+1463 \mathrm{~nm}$ OPO.

\begin{tabular}{ccccccc}
\hline Temperature $\left({ }^{\circ} \mathrm{C}\right)$ & $\mathbf{2 5}$ & $\mathbf{5 0}$ & $\mathbf{8 0}$ & $\mathbf{1 0 0}$ & $\mathbf{1 2 0}$ & $\mathbf{1 5 0}$ \\
\hline PM angle $(\theta, \phi)$ & $(54.9,0)$ & $(55,0)$ & $(55.2,0)$ & $(55.6,0)$ & $(56.1,0)$ & $(56.7,0)$ \\
\hline
\end{tabular}




\section{Measurement of Refractive Indices}

$\mathrm{BaGa}_{4} \mathrm{Se}_{7}$ is a biaxial crystal and belongs to the monoclinic space group Pc [8]. To measure its three independent principal refractive indices $n_{x}, n_{y}$, and $n_{z}$, one $\mathrm{BaGa}_{4} \mathrm{Se}_{7}$ crystal was cut into two right-angle prisms with the sides of the right angle aligned with different directions, as shown in Figure 2. The apex angles of two prisms were approximately $14.63^{\circ}$ and $18.16^{\circ}$, respectively. In our experiment, the refractive index could be calculated by using $n=\sin (\alpha+\beta) / \sin (\alpha)$, where $n$ is the principal refractive index, $\alpha$ is the apex angle of the prism, and $\beta$ is the deviation angle of refractive light. When the incident light travels perpendicular to the $b$ face of Prism 1 , refractive indices $n_{x}$ and $n_{z}$ could be measured. Refractive indices $n_{y}$ as well as $n_{x}$ could also be measured when the light travels perpendicular to the $c$ face of Prism 2.
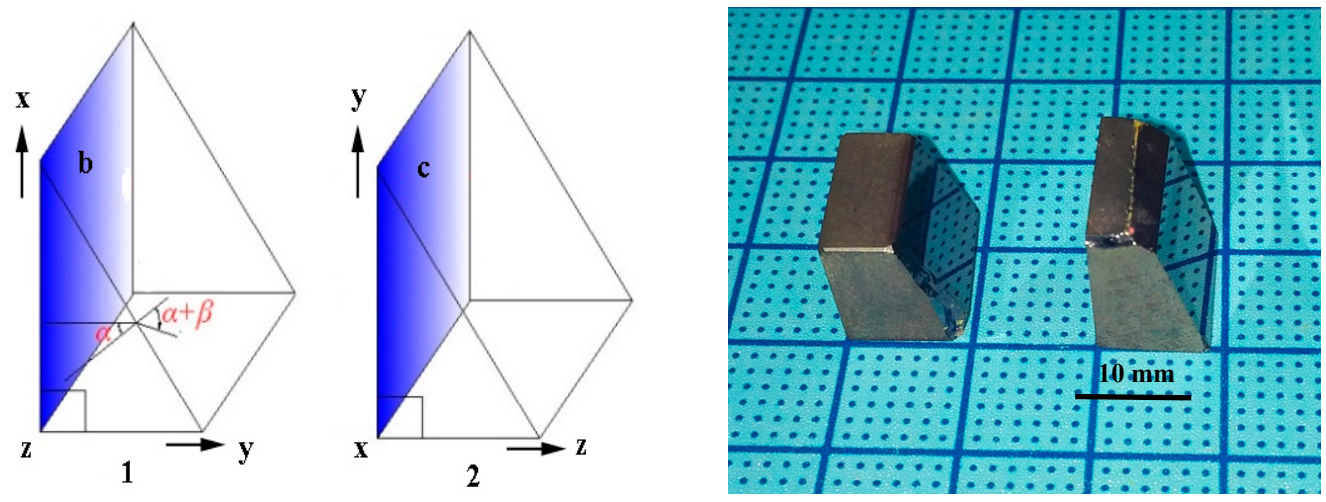

Figure 2. Schematic (left) and photograph (right) of Prism 1 and Prism 2.

Our experimental system is comprised ofa refractive index measurement instrument (SpectroMaster UV-VIS-IR, Trioptics, Wedel, Germany) with a high accuracy of $1 \times 10^{-5}$ and a homemade temperature-stabilized heating furnace with an accuracy of $\pm 0.1^{\circ} \mathrm{C}$, as shown in Figure 3 .

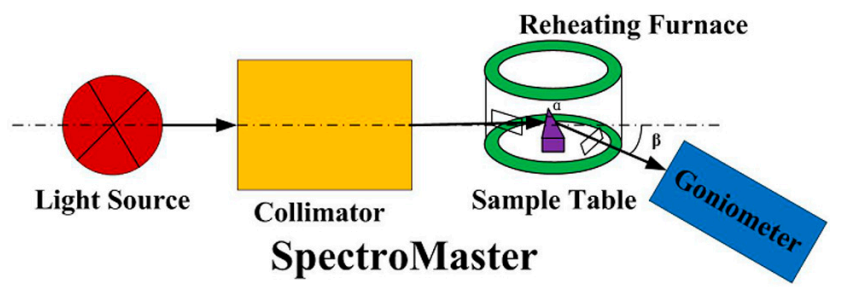

Figure 3. The experimental setup of measurement.

In the measurement, mercury lamp at wavelengths of $0.546,1.530,1.970$, and $2.325 \mu \mathrm{m}$, helium lamp at wavelengths of 0.5875 and $0.7065 \mu \mathrm{m}$, and Chromium lamp at wavelength of $0.644 \mu \mathrm{m}$ were used. The prisms were placed in a temperature-stabilized furnace, and heated to the target temperature $\left(25,50,80,100,120\right.$, and $150^{\circ} \mathrm{C}$, respectively) with $30^{\circ} \mathrm{C} / \mathrm{h}$ and allowed to reach thermal equilibrium. During the measurement process, the incident angle of the central collimator beam was defined as $0^{\circ}$. The sample table was first adjusted to be horizontal and the accurate apex angle of the prism was measured, after which the sample was aligned square to the collimator, and the goniometer was rotated manually to find the refractive signal and measure the deviation angle using the measurement program of the instrument. At each temperature, the deviation angle was usually measured four times at different wavelengths, and the results were averaged to obtain a single determination of deviation. The measured results are listed in Table 1. 


\section{Conclusions}

In summary, the thermal refractive index coefficients of BGSe crystal were measured for the first time. The temperature-dependent Sellmeier equations were fitted, and were then used to calculate PM angles for BGSe OPO crystal at different temperatures. The thermal refractive index coefficients and the temperature-dependent Sellmeier equations of BGSe crystal will be highly useful for designing a mid IR frequency conversion system based on BGSe crystal.

Acknowledgments: The work was supported by National Science Foundation of China (No. 51472251).

Author Contributions: NaixiaZhai, Bo Xu, and Lei Bai, performed the experiments; Chao Li, Jiyong Yao, and Guochun Zhang analyzed the data; Zhanggui $\mathrm{Hu}$ and Yicheng $\mathrm{Wu}$ discussedthe results.

Conflicts of Interest: The authors declare no conflict of interest.

\section{References}

1. Chung, I.; Kanatzidis, M.G. Metal chalcogenides: A rich source of nonlinear optical materials. Chem. Mater. 2013, 26, 849-869. [CrossRef]

2. Li, X.S.; Li, C.; Gong, P.F.; Lin, Z.S.; Yao, J.Y.; Wu, Y.C. $\mathrm{BaGa}_{2} \mathrm{SnSe}_{6}$ : A new phase-matchable IR nonlinear optical material with strong second harmonic generation response. J. Mater. Chem. C 2015, 3, 10998-11004. [CrossRef]

3. Isaenko, L.; Yelisseyev, A.; Lobanov, S.; Vedenyapin, V.; Krinitsyn, P.; Petrov, V. Properties of $\operatorname{LiGa}_{0.5} \operatorname{In}_{0.5} \mathrm{Se}_{2}$ : A Quaternary Chalcogenide Crystal for Nonlinear Optical Applications in the Mid-IR. Crystals 2016, 6, 85. [CrossRef]

4. Liao, J.H.; Marking, G.M.; Hsu, K.F.; Matsushita, Y.; Ewbank, M.D.; Borwick, R.; Cunningham, P.; Rosker, M.J.; Kanatzidis, M.G. $\alpha$ - and $\beta-\mathrm{A}_{2} \mathrm{Hg}_{3} \mathrm{M}_{2} \mathrm{~S}_{8}(\mathrm{~A}=\mathrm{K}, \mathrm{Rb} ; \mathrm{M}=\mathrm{Ge}, \mathrm{Sn})$ : Polar quaternary chalcogenides with strong nonlinear optical response. J. Am. Chem. Soc. 2003, 125, 9484-9493. [CrossRef] [PubMed]

5. Boyd, G.D.; Kasper, H.M.; McFee, J.H.; Storz, F.G. Linear and nonlinear optical properties of some ternary selenides. IEEE J. Quantum Electron. 1972, 12, 900-908. [CrossRef]

6. Boyd, G.D.; Buehler, E.; Storz, F.G. Linear and nonlinear optical properties of $\mathrm{ZnGeP}_{2}$ and CdSe. Appl. Phys. Lett. 1971, 18, 301-304. [CrossRef]

7. Creeden, D.; Ketteridge, P.A.; Budni, P.A.; Setzler, S.D.; Young, Y.E.; McCarthy, J.C.; Zawilski, K.; Schunemann, P.G.; Pollak, T.M.; Chicklis, E.P.; et al. Mid-infrared $\mathrm{ZnGeP}_{2}$ parametric oscillator directly pumped by a pulsed $2 \mu \mathrm{m}$ Tm-doped fiber laser. Opt. Lett. 2008, 33, 315-317. [CrossRef] [PubMed]

8. Yao, J.Y.; Mei, D.J.; Bai, L.; Lin, Z.S.; Yin, W.L.; Fu, P.Z.; Wu, Y.C. BaGa ${ }_{4} \mathrm{Se}_{7}$ : A New Congruent-Melting IR Nonlinear Optical Material. Inorg. Chem. 2010, 49, 9212-9216. [CrossRef] [PubMed]

9. Badikov, V.; Badikov, D.; Shevyrdyaeva, G.; Tyazhev, A.; Marchev, G.; Panyutin, V.; Petrov, V.; Kwasniewski, A. Phase-matching properties of $\mathrm{BaGa}_{4} \mathrm{~S}_{7}$ and $\mathrm{BaGa}_{4} \mathrm{Se}_{7}$ : Wide-bandgap nonlinear crystals for the mid-infrared. Phys. Status Solidi RRL 2011, 5, 31-33. [CrossRef]

10. Yao, J.Y.; Yin, W.L.; Feng, K.; Li, X.M.; Mei, D.J.; Lu, Q.M.; Ni, Y.B.; Zhang, Z.W.; Hu, Z.G.; Wu, Y.C. Growth and characterization of $\mathrm{BaGa}_{4} \mathrm{Se}_{7}$ crystal. J. Cryst. Growth 2012, 346, 1-4. [CrossRef]

11. Zhang, X.; Yao, J.Y.; Yin, W.L.; Zhu, Y.; Wu, Y.C.; Chen, C.T. Determination of the nonlinear optical coefficients of the $\mathrm{BaGa}_{4} \mathrm{Se}_{7}$ crystal. Opt. Express 2015, 23, 552-558. [CrossRef] [PubMed]

12. Boursier, E.; Segonds, P.; Debray, J.; Inacio, P.L.; Panyutin, V.; Badikov, V.; Badikov, D.; Petrov, V.; Boulanger, B. Angle noncritical phase-matched second-harmonic generation in the monoclinic crystal $\mathrm{BaGa}_{4} \mathrm{Se}_{7}$. Opt. Lett. 2015, 40, 4591-4594. [CrossRef] [PubMed]

13. Yang, F.; Yao, J.Y.; Xu, H.Y.; Feng, K.; Yin, W.L.; Li, F.Q.; Yang, J.; Du, S.F.; Peng, Q.J.; Zhang, J.Y.; et al. High efficiency and high peak power picosecond mid-infrared optical parametric amplifier based on $\mathrm{BaGa}_{4} \mathrm{Se}_{7}$ crystal. Opt. Lett. 2013, 38, 3903-3905. [CrossRef] [PubMed]

14. Yang, F.; Yao, J.Y.; Xu, H.Y.; Zhang, F.F.; Zhai, N.X.; Lin, Z.H.; Zong, N.; Peng, Q.J.; Zhang, J.Y.; Cui, D.F.; et al. Midinfrared Optical Parametric Amplifier With 6.4-11 $\mu \mathrm{m}$ Range Based on $\mathrm{BaGa}_{4} \mathrm{Se}_{7}$. IEEE Photonics Technol. Lett. 2015, 27, 1100-1103. [CrossRef] 
15. Yuan, J.H.; Li, C.; Yao, B.Q.; Yao, J.Y.; Duan, X.M.; Li, Y.Y.; Shen, Y.J.; Wu, Y.C.; Cui, Z.; Dai, T.Y. High power, tunable mid-infrared $\mathrm{BaGa}_{4} \mathrm{Se}_{7}$ optical parametric oscillator pumped by a $2.1 \mu \mathrm{m}$ Ho:YAG laser. Opt. Express 2016, 24, 6083-6087. [CrossRef] [PubMed]

16. Boursier, E.; Segonds, P.; Menaert, B.; Badikov, V.; Panyutin, V.; Badikov, D.; Petrov, V.; Boulanger, B. Phase-matching directions and refined Sellmeier equations of the monoclinic acentric crystal $\mathrm{BaGa}_{4} \mathrm{Se}_{7}$. Opt. Lett. 2016, 41, 2731-2734. [CrossRef] [PubMed]

17. Kostyukova, N.Y.; Boyko, A.A.; Badikov, V.; Badikov, D.; Shevyrdyaeva, G.; Panyutin, V.; Marchev, G.M.; Kolker, D.B.; Petrov, V. Widely tunable in the mid-IR $\mathrm{BaGa}_{4} \mathrm{Se}_{7}$ optical parametric oscillator pumped at 1064 nm. Opt. Lett. 2016, 41, 3667-3670. [CrossRef] [PubMed]

(C) 2017 by the authors. Licensee MDPI, Basel, Switzerland. This article is an open access article distributed under the terms and conditions of the Creative Commons Attribution (CC BY) license (http:/ / creativecommons.org/licenses/by/4.0/). 